\title{
Editorial: The Asian Monsoon
}

\author{
Lin Wang $^{1 *}$, Haishan Chen ${ }^{2}$, Jasti S. Chowdary ${ }^{3}$, Kyung-Ja Ha ${ }^{4}$, Yoshiyuki Kajikawa ${ }^{5}$ and \\ Gill Martin ${ }^{6}$
}

${ }^{1}$ Center for Monsoon System Research, Institute of Atmospheric Physics, Chinese Academy of Sciences, Beijing, China, ${ }^{2}$ School of Atmospheric Sciences, Nanjing University of Information Science and Technology, Nanjing, China, ${ }^{3}$ Indian Institute of Tropical Meteorology, Pune, India, ${ }^{4}$ Center for Climate Physics, Institute for Basic Science, and Department of Atmospheric Sciences, Pusan National University, Busan, South Korea, ${ }^{5}$ RIKEN Center for Computational Science, and Research Center for Urban Safety and Security, Kobe University, Kobe, Japan, ${ }^{6}$ Met Office Hadley Centre, Exeter, United Kingdom

Keywords: monsoon, ENSO, interannual variability, interdecadal variability, land-atmopshere interactions, air-sea interactions

\section{Editorial on the Research Topic}

\section{The Asian Monsoon}

The Asian monsoon is an essential component of the global climate system (Trenberth et al., 2006). Its evolution and variability can significantly influence the vegetation, populations, economies, and even cultures that inhabit Asian monsoon regions, which prevails from the Indian sub-continent to Southeast and East Asia. The monsoon-related natural hazards, such as flooding, droughts, heatwaves, and blizzards, significantly impact society, and human livelihood (Wang, 2006). Therefore, it is essential to understand the variability and mechanism of the Asian monsoon so that skillful forecasts, predictions, and reasonable future projections can be made accordingly.

The Asian monsoon consists of both summer and winter counterparts (Ju and Slingo, 1995; Chang et al., 2006; Wang and Lu, 2017) and several sub-systems, including the Indian monsoon, the East Asian monsoon, and the western North Pacific monsoon (Wang and LinHo, 2002). These subsystems have strong mutual linkages and vary from synoptic to multidecadal and longer time scales. They interact with the Earth's ocean, land, atmosphere, the biosphere, among others, via complex coupled processes (Meehl, 1994; Webster et al., 1998; Gadgil, 2003; Goswami, 2005; Yihui and Chan, 2005; Huang et al., 2007; Ha et al., 2012; Huang et al., 2012; Chen et al., 2019). It is essential to know how and why the current state-of-the-art numerical models capture these processes before making forecasts and predictions. This issue becomes increasingly crucial in light of global climate change.

In this Research Topic, the main objective was to present some recent advances and identify some remaining gaps in our knowledge on all aspects of the Asian monsoon. Sixteen papers were published after peer reviews. Most of them focus on the summer monsoon and discuss the role of air-sea interactions in the monsoon variability on the interannual timescale. The El Nino-Southern Oscillation (ENSO) is an essential driver for the Indian summer monsoon (ISM) precipitation (Ju and Slingo, 1995; Gadgil, 2003), and its relationship with the ISM underwent decadal weakening in the late 1970s (Kumar et al., 1999) and recovered recently (Yang and Huang, 2021; Yu et al., 2021). Bódai et al. revisit the unstable ENSO-ISM relationship and the underlying mechanism with the help of large-ensemble simulations and discuss its nonlinearity and nonergodicity. Son et al. further claim the essential role of the ISM precipitation in exciting a dominant teleconnection in boreal summer, the Silk Road pattern (SRP, Lu et al., 2002; Enomoto et al., 2003; Chowdary et al., 2019) by showing how the Rossby wave source is generated by the ISM-related diabatic heating. Although the SRP is an internal mode of the atmosphere (Yasui and Watanabe, 2010), it may be excited or amplified by atmospheric external forcing or resonance (e.g., Yasui and Watanabe, 2010; Wang et al., 2017), leading to longer atmospheric residence time over India and thereby more frequent extreme events (Lakshmi Kumar et al.). 
The influence of ENSO on the East Asian summer monsoon (EASM) is also crucial (Xie et al., 2016; Li et al., 2017; Zhang et al., 2017). It shows significant diversity regarding the spatial patterns of ENSO (Feng et al., 2011; Yuan and Yang, 2012), the decaying speed of ENSO (Chen et al., 2012; Feng et al., 2014; Zhou et al., 2019), the background state (Feng et al., 2014), the different configurations with other oceanic signals (Xie et al., 2009; Chen et al., 2016; Feng et al., 2020), and many others. Zhang et al. further attribute this diversity to the persistence and transition speed of ENSO. Li et al. take Hong Kong as an example and link this diversity to the North Atlantic sea surface temperature. Besides ENSO, J. Xu et al. claim that the Indian Ocean dipole (Saji et al., 1999) can influence the EASM precipitation and thereby the rice yield in Jiangsu, a province in eastern China. You et al. suggest that the thermal state of the tropical western Pacific can change the meridional temperature gradient and the onset of the EASM. Huang et al. reveal that the accumulation effect of the intra-seasonal oscillation over the tropical western Pacific can change the meridional location of the western Pacific subtropical high, a crucial circulation system of the EASM. Zeng et al. suggest that the linkage between the onset dates of the ISM and the EASM strengthened after the late 1970s, which is attributed to the Indian Ocean basin warming. Liu et al. suggest that the Atlantic Multidecadal Variability and its footprint in the Indian Ocean may lead to multidecadal seesaw in the Hadley Circulation's strength between Northern and Southern Hemispheres and further to changes in land precipitation over monsoon regions. Wen et al. reveal the influences of the North Pacific Victoria Mode on the MaddenJulian Oscillation, an essential factor influencing the Asian monsoon on the intraseasonal timescale.

Several papers in the Research Topic discuss land-surface processes in the EASM variability, which is another essential aspect for the Asian monsoon (Webster et al., 1998; Xue et al., 2004; Yasunari, 2007). Wang et al. review the impacts of the soil freeze-thaw process and snow melting over the Tibetan Plateau on the EASM. Liang et al. report a decadal change in the relationship between the Tibetan Plateau temperature and summer precipitation over the South China Sea. Xu et al. identify a relationship between the Eurasian snow melting in spring and the EASM and suggest the mechanism involving the

\section{REFERENCES}

Chang, C.-P., Wang, Z., and Hendon, H. (2006). “The Asian winter Monsoon,” in The Asian Monsoon. Springer Berlin Heidelberg, 89-127.

Chen, W., Park, J.-K., Dong, B., Lu, R., and Jung, W.-S. (2012). The Relationship between El Niño and the Western North Pacific Summer Climate in a Coupled GCM: Role of the Transition of El Niño Decaying Phases. J. Geophys. Res. 117. doi:10.1029/2011jd017385

Chen, W., Wang, L., Feng, J., Wen, Z., Ma, T., Yang, X., et al. (2019). Recent Progress in Studies of the Variabilities and Mechanisms of the East Asian Monsoon in a Changing Climate. Adv. Atmos. Sci. 36, 887-901. doi:10.1007/ s00376-019-8230-y

Chen, Z., Wen, Z., Wu, R., Lin, X., and Wang, J. (2016). Relative Importance of Tropical SST Anomalies in Maintaining the Western North Pacific Anomalous Anticyclone during El Niño to La Niña Transition Years. Clim. Dyn. 46, 1027-1041. doi:10.1007/s00382-015-2630-1 changes in the baroclinicity and transient eddy forcing. Especially, Lau et al. report a fascinating result on the role of the dust from Middle East deserts in affecting the Asian summer monsoon. They highlight that the dust-cloud-radiation-precipitation dynamical feedback on subseasonal-to-seasonal timescale can lead to anomalous diabatic heating over the Pakistan/Northwest India region and excite atmospheric Rossby waves, which shifts the whole Asian summer monsoon westward.

The Research Topic is overall successful, but it has deficiencies. For example, most of the articles focus on the air-sea interaction aspect of the monsoon on the seasonal timescale and longer. Other processes and timescales, such as the land-atmosphere interactions, internal atmospheric processes, and subseasonal variabilities or extremes, which are also essential for the Asian monsoon, were less discussed. There is even no paper on the Asian winter monsoon, an indispensable member of the Asian monsoon, and the Asian monsoon projection and its uncertainties, an increasing concern of both the scientific community and the public. Although this Research Topic only contains a very small sample size, it reflects the current status of the monsoon research to some extent, and a more balanced study on the Asian monsoon in the future is recommended.

\section{AUTHOR CONTRIBUTIONS}

All authors listed have made a substantial, direct, and intellectual contribution to the work and approved it for publication.

\section{FUNDING}

LW is supported by the National Natural Science Foundation of China $(41925020,41721004)$. HC is supported by the National Natural Science Foundation of China (41625019).

\section{ACKNOWLEDGMENTS}

We thank the support of the editorial office from the preparation to the publication processes of this Research Topic.

Chowdary, J. S., Hu, K., Srinivas, G., Kosaka, Y., Wang, L., and Rao, K. K. (2019). The Eurasian Jet Streams as Conduits for East Asian Monsoon Variability. Curr. Clim. Change Rep. 5, 233-244. doi:10.1007/s40641-019-00134-x

Enomoto, T., Hoskins, B. J., and Matsuda, Y. (2003). The Formation Mechanism of the Bonin High in August. Q. J. R. Meteorol. Soc. 129, 157-178. doi:10.1256/qj.01.211

Feng, J., Chen, W., Tam, C.-Y., and Zhou, W. (2011). Different Impacts of El Niño and El Niño Modoki on China Rainfall in the Decaying Phases. Int. J. Climatol. 31, 2091-2101. doi:10.1002/joc.2217

Feng, J., Chen, W., and Wang, X. (2020). Reintensification of the Anomalous Western North Pacific Anticyclone during the El Niño Modoki Decaying Summer: Relative Importance of Tropical Atlantic and Pacific SST Anomalies. J. Clim. 33, 3271-3288. doi:10.1175/jcli-d-19-0154.1

Feng, J., Wang, L., and Chen, W. (2014). How Does the East Asian Summer Monsoon Behave in the Decaying Phase of El Niño during Different PDO Phases? J. Clim. 27, 2682-2698. doi:10.1175/jcli-d-13-00015.1

Gadgil, S. (2003). The indianmonsoon Anditsvariability. Annu. Rev. Earth Planet Sci. 31, 429-467. doi:10.1146/annurev.earth.31.100901.141251 
Goswami, B. N. (2005). South Asian Monsoon. Intraseasonal Variability in the Atmosphere-Ocean Climate System. Editors W. K. M. Lau and D. E. Waliser (Springer Berlin Heidelberg), 19-61.

Ha, K.-J., Heo, K.-Y., Lee, S.-S., Yun, K.-S., and Jhun, J.-G. (2012). Variability in the East Asian Monsoon: a Review. Met. Apps. 19, 200-215. doi:10.1002/ met. 1320

Huang, R., Chen, J., and Huang, G. (2007). Characteristics and Variations of the East Asian Monsoon System and its Impacts on Climate Disasters in China. Adv. Atmos. Sci. 24, 993-1023. doi:10.1007/s00376-007-0993-x

Huang, R., Chen, J., Wang, L., and Lin, Z. (2012). Characteristics, Processes, and Causes of the Spatio-Temporal Variabilities of the East Asian Monsoon System. Adv. Atmos. Sci. 29, 910-942. doi:10.1007/s00376-012-2015-x

Ju, J., and Slingo, J. (1995). The Asian Summer Monsoon and ENSO. Q.J R. Met. Soc. 121, 1133-1168. doi:10.1002/qj.49712152509

Kumar, K. K., Rajagopalan, B., and Cane, M. A. (1999). On the Weakening Relationship between the Indian Monsoon and ENSO. Science 284, 2156-2159. doi:10.1126/science.284.5423.2156

Li, T., Wang, B., Wu, B., Zhou, T., Chang, C.-P., and Zhang, R. (2017). Theories on Formation of an Anomalous Anticyclone in Western North Pacific during El Niño: A Review. J. Meteorol. Res. 31, 987-1006. doi:10.1007/s13351-0177147-6

Lu, R.-Y., Oh, J.-H., and Kim, B.-J. (2002). A Teleconnection Pattern in Upper-Level Meridional Wind over the North African and Eurasian Continent in Summer. Tellus A. 54, 44-55. doi:10.1034/j.16000870.2002.00248.x

Meehl, G. A. (1994). Coupled Land-Ocean-Atmosphere Processes and South Asian Monsoon Variability. Science 266, 263-267. doi:10.1126/science.266.5183.263

Saji, N. H., Goswami, B. N., Vinayachandran, P. N., and Yamagata, T. (1999). A Dipole Mode in the Tropical Indian Ocean. Nature 401, 360-363. doi:10.1038/ 43854

Trenberth, K. E., Hurrell, J. W., and Stepaniak, D. P. (2006). “The Asian Monsoon: Global Perspectives," in The Asian Monsoon. Springer Berlin Heidelberg, 67-87.

Wang, B., and LinHo (2002). Rainy Season of the Asian-Pacific Summer Monsoon*. J. Clim. 15, 386-398. doi:10.1175/1520-0442(2002) $015<038610.1175 / 1520-0442(2002) 015<0386$ :rsotap $>2.0 . c 0 ; 2$

Wang, B. (2006). The Asian Monsoon. Springer, 845.

Wang, L., and Lu, M.-M. (2017). “The East Asian Winter Monsoon," in The Global Monsoon System: Research and Forecast. 3 ed. Editors C.-P. Chang, H.-C. Kuo, N.-C. Lau, R. H. Johnson, B. Wang, and M. C. Wheeler, 51-61. doi:10.1142/ 9789813200913_0005

Wang, L., Xu, P., Chen, W., and Liu, Y. (2017). Interdecadal Variations of the Silk Road Pattern. J. Clim. 30, 9915-9932. doi:10.1175/jcli-d-17-0340.1

Webster, P. J., Magaña, V. O., Palmer, T. N., Shukla, J., Tomas, R. A., Yanai, M., et al. (1998). Monsoons: Processes, Predictability, and the Prospects for Prediction. J. Geophys. Res. 103, 14451-14510. doi:10.1029/97jc02719

Xie, S.-P., Hu, K., Hafner, J., Tokinaga, H., Du, Y., Huang, G., et al. (2009). Indian Ocean Capacitor Effect on Indo-Western Pacific Climate during the Summer Following El Niño. J. Clim. 22, 730-747. doi:10.1175/2008jcli2544.1
Xie, S.-P., Kosaka, Y., Du, Y., Hu, K., Chowdary, J. S., and Huang, G. (2016). Indowestern Pacific Ocean Capacitor and Coherent Climate Anomalies in post-ENSO Summer: a Review. Adv. Atmos. Sci. 33, 411-432. doi:10.1007/s00376-015-5192-6

Xue, Y., Juang, H.-M. H., Li, W.-P., Prince, S., DeFries, R., Jiao, Y., et al. (2004). Role of Land Surface Processes in Monsoon Development: East Asia and West Africa. J. Geophys. Res. 109. doi:10.1029/2003jd003556

Yang, X., and Huang, P. (2021). Restored Relationship between ENSO and Indian Summer Monsoon Rainfall Around 1999/2000. The Innovation 2, 100102. doi:10.1016/j.xinn.2021.100102

Yasui, S., and Watanabe, M. (2010). Forcing Processes of the Summertime Circumglobal Teleconnection Pattern in a Dry AGCM. J. Clim. 23, 2093-2114. doi:10.1175/2009jcli3323.1

Yasunari, T. (2007). Role of Land-Atmosphere Interaction on Asian Monsoon Climate. J. Meteorol. Soc. Jpn. 85B, 55-75. doi:10.2151/jmsj.85B.55

Yihui, D., and Chan, J. C. L. (2005). The East Asian Summer Monsoon: an Overview. Meteorol. Atmos. Phys. 89, 117-142. doi:10.1007/s00703-005-0125-Z

Yu, S. Y., Fan, L., Zhang, Y., Zheng, X. T., and Li, Z. (2021). Reexamining the Indian Summer Monsoon Rainfall-ENSO Relationship from its Recovery in the $21 \mathrm{St}$ Century: Role of the Indian Ocean SST Anomaly Associated with Types of ENSO Evolution. Geophys. Res. Lett. 48, e2021GL092873. doi:10.1029/ $2021 \mathrm{gl} 092873$

Yuan, Y., and Yang, S. (2012). Impacts of Different Types of El Niño on the East Asian Climate: Focus on ENSO Cycles. J. Clim. 25, 7702-7722. doi:10.1175/jclid-11-00576.1

Zhang, R., Min, Q., and Su, J. (2017). Impact of El Niño on Atmospheric Circulations over East Asia and Rainfall in China: Role of the Anomalous Western North Pacific Anticyclone. Sci. China Earth Sci. 60, 1124-1132. doi:10.1007/s11430-016-9026-X

Zhou, X., Liu, F., Wang, B., Xiang, B., Xing, C., and Wang, H. (2019). Different Responses of East Asian Summer Rainfall to El Niño Decays. Clim. Dyn. 53, 1497-1515. doi:10.1007/s00382-019-04684-6

Conflict of Interest: The authors declare that the research was conducted in the absence of any commercial or financial relationships that could be construed as a potential conflict of interest.

Publisher's Note: All claims expressed in this article are solely those of the authors and do not necessarily represent those of their affiliated organizations, or those of the publisher, the editors and the reviewers. Any product that may be evaluated in this article, or claim that may be made by its manufacturer, is not guaranteed or endorsed by the publisher.

Copyright (C) 2021 Wang, Chen, Chowdary, Ha, Kajikawa and Martin. This is an open-access article distributed under the terms of the Creative Commons Attribution License (CC BY). The use, distribution or reproduction in other forums is permitted, provided the original author(s) and the copyright owner(s) are credited and that the original publication in this journal is cited, in accordance with accepted academic practice. No use, distribution or reproduction is permitted which does not comply with these terms. 